\title{
ORIENTAÇÃO PARA O PLANEJAMENTO DIDÁTICO PEDAGÓGICO DE UM CURSO DE PÓS-GRADUAÇÃO NA FORMAÇÃO DO PROFESSOR EM EAD
}

\author{
ORIENTATION FOR EDUCATIONAL PLANNING TEACHING FROM A COURSE \\ OF THE GRADUATE EDUCATION TEACHER IN EAD
}

\section{ORIENTACIÓN PARA LA ENSEÑANZA DE PLANEAMIENTO DE LA EDUCACIÓN EN EL CURSO DE LA FORMACIÓN DOCENTE LICENCIADO EN EAD}

\section{RESUMO}

\author{
Helcimara Affonso Souza ${ }^{1}$ \\ Sonia Vilela Bueno ${ }^{2}$ \\ Evelyn Cássia Pereira Santiago ${ }^{3}$ \\ Delaine Gibeli Viana ${ }^{4}$ \\ Cristiana Bueno Almeida ${ }^{5}$
}

Introducação: Há algum tempo, temos percebido o reduzido conhecimento dos interessados na Educação a Distância $(\mathrm{EaD})$ em relação ao planejamento didático-pedagógico para elaboração de um curso nesta modalidade de ensino. Baseados nesta inquietação e em referenciais teóricos e práticos sobre estas questões, propomos o presente trabalho. Objetivo: Orientar como elaborar um plano de ensino de uma disciplina de $\mathrm{EaD}$ em um Programa de Pós-Graduação Stricto Sensu de uma Universidade Pública, de modo a chamar a atenção à necessidade de possibilitar ao aluno, futuro professor, o conhecimento básico sobre EaD e discutir tópicos elementares constantes deste planejamento referentes a sua construção, a partir de eixos temáticos e tendo como plano de fundo a abordagem interacionista.

Metodologia: Estudo qualitativo, de cunho descritivo-analítico e documental. Resultados e Considerações finais: Observa-se que a utilização dos Eixos facilita o entendimento do conteúdo programático e permite uma maior flexibilidade, constituída a partir da interação

\footnotetext{
${ }^{1}$ Administradora, especialista em EAD, mestre em Engenharia de Produção (USP). Docente universitária há 8 anos, coordenadora de curso de graduação na modalidade EAD na UNISEB. Diretoria da Mapear Des. Empresarial, responsável pelos projetos de liderança e gestão de equipes.E-mail: mara.souza@uniseb.com.br

2 EERP/USP-Email: smvbueno@eerp.usp.br

3 EERP/USP-E-mail: ecpcosta@yahoo.com.br

4 Uniseb-E-mail: delaine.viana@uniseb.com.br

${ }^{5}$ EERP/USP-E-mail: cristianabueno@yahoo.com.br 
Sousa HA,Bueno SV,Santiago ECP et al Orientação para o planejamento didático pedagógico de um curso...

com o aluno. Considera-se de extrema relevância esta produção no que concerne a formação de professores/tutores/alunos em EaD, considerando os elementos-chave do planejamento, assim como, a divulgação de tais disciplinas em meio a Instituições Públicas de Ensino.

Palavras-chave: Planejamento de disciplina em EaD; Eixos Temáticos; Plano didáticopedagógico; Abordagem Interacionista.

\begin{abstract}
Introduction: For some time, we have reduced the perceived knowledge of stakeholders in Distance Education (DE) in relation to planning didactic-pedagogic preparation for a course of this type of education. Based on this concern and in theoretical and practical about these issues, we propose the present work. Objective: Advise how to prepare a syllabus of a discipline of distance education in Post-graduate studies at a public university in order to draw attention to the need to enable the student, future teacher, basic knowledge about distance education and discuss topics concerning basic constants of this planning its construction, from themes and having as background the interactionist approach. Methodology: A qualitative study, a descriptive-analytical and documentary. Results and Final Thoughts: It is observed that the use of axes facilitates the understanding of the curriculum and allows for greater flexibility, formed from the interaction with the student. It is extremely important that production regarding the training of teachers / tutors / students in distance education, considering the key elements of planning as well as the disclosure of such disciplines amid Public Institutions of Higher Education.
\end{abstract}

Keywords: Planning discipline in distance education; Thematic Groups; Plan didacticpedagogic; Interactionist Approach.

\title{
1- Introdução
}

Atualmente, o Ensino a Distância $(\mathrm{EaD})$ vem ganhando cada vez mais espaço nas escolas do Brasil, sobremaneira, no ensino superior. Haja vista, haver um ancoramento previsto pela Lei 9394/96, das Diretrizes e Bases da Educação Nacional (LDB) e o Decreto 5.622 de $19 / 12 / 05^{[1]}$.

Mais do que necessária, trata-se de uma modalidade metodológica que se ajusta adequadamente aos pressupostos do mundo globalizado em que vivemos nos tempos de pósmodernidade. Soma-se a isto, a questão da extensão geográfica em que o nosso país se insere, 
Sousa HA,Bueno SV,Santiago ECP et al Orientação para o planejamento didático pedagógico de um curso...

com grandes diversidades econômicas e estruturais, demandando, dos centros de referência de ensino e pesquisa da nação, apoio no que concerne ao conhecimento, competências e habilidades, como também, às tecnologias educacionais/ virtuais e ambientais, dentre outros aspectos.

Isto posto, pretendemos inicialmente, nesta proposta, sensibilizar e preparar, teoricamente, os docentes e pós-graduandos para a elaboração adequada do planejamento didático-pedagógico desta tecnologia educacional. Isto por si, justifica o presente trabalho.

\section{2 - Objetivos}

Relatar a experiência de uma proposta para o planejamento didático-pedagógico (com seus elementos fundamentais: objetivos, conteúdo, estratégias, avaliação e referências, além das funções do professor, do tutor e do aluno), num curso de pós-graduação, visando, minimamente, um preparo adequado para a estruturação de um Curso a Distância.

Levar em consideração, ainda, a possibilidade do aluno desenvolver um arcabouço de conhecimentos gerais neste sentido, enquanto modalidade educacional, trabalhando os principais pontos teóricos e evidenciando as diversas ferramentas virtuais e inovadoras para um efetivo funcionamento do curso.

\section{3 - Breve Revisão bibliográfica}

$\mathrm{Na}$ contemporaneidade, o processo de planejamento do ensino têm sido foco de debates e reconstruções, que justificam-se por inúmeras razões, como a não coadunação entre os objetivos educacionais propostos nos currículos de alguns cursos e a realidade social em que estão inseridos; ou ainda, a utilização de recursos pelo professor enquanto meros equipamentos, sem a devida adequação ao conteúdo planejado.

Em relação a metodologia, o aluno, usualmente, encontra-se na posição de receptor de informações, sem ter espaço a um processamento e análise crítica do conteúdo. Isto vem de encontro à realidade das avaliações vigentes, que propiciam apenas a soma dos conteúdos assimilados, representando, assim, o abafamento de sua verificação de conhecimentos

autênticos, criatividade, criticidade, autonomia e emancipação democrática ${ }^{[2,7,13,14]}$.

Esta realidade, aos poucos, vem se modificando e, geralmente, se opõe àquela encontrada na Educação a Distância $(\mathrm{EaD})$, que utiliza práticas "para atender às diversidades de currículos e de estudantes e para responder as demandas nacionais, regionais e locais" (p. 
17) ${ }^{[3]}$. Dessa forma, a proposta da EaD tem despontado como um meio de formação do futuro, que valoriza o aprender, o aluno e suas características/ historicidade.

Contudo, o mero uso de ferramentas tecnológicas não caracteriza qualidade na EaD. Para que haja eficiência e eficácia neste processo, , ela necessita de uma proposta didáticopedagógica com diferenças e semelhanças a modalidade presencial e até mais exigente que esta $^{[4]}$.

Este ponto torna-se ainda mais relevante quando nos referimos a formação de professores. Torna-se imperativo uma educação que valorize professores reflexivosinvestigativos, que estejam em um processo contínuo educativo, o qual reflete sobre seu saber e fazer ${ }^{[5]}$.

O uso da tecnologia nas instituições de ensino brasileiras é valorosa para esta formação e capacitação, requerindo "o estudo de propostas teórico-metodológicas e uma ampla divulgação de experiências em EAD, bem como uma reflexão das mesmas" (p.17) ${ }^{[6]}$.

\section{4 - Metodologia}

Trata-se de um relato de experiência, de cunho qualitativo, descritivo-analítico e documental, que orienta e propõe a elaboração e estruturação de uma proposta no preparo de alunos de um curso de pós-graduação frequencial para a formação didático-pedagógica em $\mathrm{EaD}$.

O presente trabalho foi analisado por categorização, utilizando as características dos eixos temáticos, baseados em Paulo Freire e Bueno ${ }^{[7]}$.

\section{1 - Procedimento (passos)}

a) Destinação do curso presencial em nível de Pós-Graduação.

b) Busca da literatura sobre a temática em foco, distribuída entre os descritores EaD, planejamento didático-pedagógico, ferramentas virtuais, etc.

c) Fundamentação teórica sobre o tema em apreço.

d) Seleção do material a ser utilizado, buscando eixos temáticos.

e) Análise e discussão do conteúdo, tendo em vista a formação dos alunos de pósgraduação para os aspectos didático-pedagógicos, devendo culminar com relatórios em portfólios e pesquisa na área.

f) Elaboração da proposta final.

g) Divulgação e publicação dos achados. 


\section{2 - Plano da disciplina}

Esta seção tem como objetivo orientar, elaborar e mostrar a estruturação utilizada contemplando a apresentação da disciplina, descrição dos objetivos, justificativa, a ementa, o conteúdo programático, a metodologia, a estratégia e ferramentas de apoio, os critérios de avaliação e as referências:

\subsection{1 - Apresentação da disciplina}

NOME DA DISCIPLINA: Educação à distância (Exemplo)

PROGRAMA/ÁREA:

No DE CRÉDITOS: 3 (45h)

Aulas Teóricas: 5; Práticas, Seminários e Outros: 5; Horas de Estudo:

5 DURAÇÃO: 3 semanas

\section{DOCENTE(S) RESPONSÁVEL(EIS):}

\subsection{2 - Objetivos:}

Possibilitar ao aluno de Pós-Graduação o conhecimento geral sobre Educação a Distância, enquanto modalidade educacional, trabalhando os principais pontos teóricos, bem como, seu planejamento didático-pedagógico, considerando, ainda, as diversas ferramentas virtuais e inovadoras para o efetivo funcionamento.

\subsection{3 - Justificativa:}

Atualmente, o Ensino a Distância $(\mathrm{EaD})$ vem ganhando cada vez mais espaço nas escolas do Brasil, sobremaneira, no ensino superior. Haja vista, haver um ancoramento previsto pelo Decreto 5.622 de 19/12/05 ${ }^{[1]}$.

Mais do que necessária, trata-se de uma modalidade metodológica que se ajusta adequadamente aos tempos atuais. Soma-se a isto, a questão da extensão geográfica do Brasil e de suas diversidades sócio-econômicas, culturais e políticas, demandando das academias de ensino, pesquisa e extensão apoio no que concerne ao conhecimento/ competência, habilidades, bem como às tecnologias educacionais/ virtuais, entre outros aspectos.

Pretendemos, pois, sensibilizar e preparar teoricamente os pós-graduandos para a elaboração adequada do planejamento didático desta tecnologia educacional. Isto por si, justifica a presente disciplina. 
4.2.4 - Conteúdo (ementa) - A ementa corresponde ao sumário ou resumo dos temas que serão abordados:

\section{- EIXO 1: GESTÃO, PLANEJAMENTO E ESTRUTURAÇÃO DA EAD}

- $\quad$ História, fundamentação e conceitos da $\mathrm{EaD}$.

- $\quad$ Modelos de $1^{\mathrm{a}}, 2^{\mathrm{a}}$ e $3^{\mathrm{a}}$ geração em EaD.

- $\quad$ Educação em EaD e seus pressupostos.

- $\quad$ Estruturação (tipos) e organização de cursos na EaD.

- $\quad$ Decreto n 5622 (19/12/2005): LDB (Processos de Ensino e Aprendizagem na utilização de meios das TICs com atividades educativas: professor-aluno).

- Detalhamento do planejamento didático-pedagógico e competências em EaD.

\section{- EIXO 2: OS SUJEITOS NO EAD}

- $\quad$ A emancipação do sujeito em EaD.

- $\quad$ Recursos Humanos/ Multidisciplinar (papeis e funções).

- $\quad$ Professor/Tutor/aluno e a interatividade da relação dialógica em EaD.

\section{- EIXO 3: ESTRATÉGIAS ATUAIS NA EAD}

- $\quad$ Referenciais de Qualidade de Cursos a Distância.

- $\quad$ Eixos conceituais: Mediatização, autonomia, autoaprendizagem, interatividade e interação.

- Diferenças entre Presencial e Semipresencial em EaD.

\section{- EIXO 4: INSTRUMENTOS E RECURSOS DIDÁTICO-PEDAGÓGICOS}

- Design Institucional como estratégia na construção do ambiente virtual de aprendizagem.

•Elaboração dos objetivos, conteúdos, estratégias e avaliação em EaD

- Metodologia de Ensino (métodos e técnicas): internet, videoconferência, tutoria, TV Câmara, depoimentos, correio, telefonia, etc.

- Seleção e Preparação de material didático-pedagógico (elementos visuais, verbais, entre outros).

\section{- EIXO 5: TENDÊNCIAS DO EAD}

- $\quad$ Modalidade em EaD na Saúde/ Enfermagem.

- $\quad$ Futuro da Educação: comunicação digital.

- $\quad$ Novos Paradigmas em EaD. 
- $\quad$ Aprendizagem colaborativa.

- $\quad$ Pesquisa em EaD.

4.2.5 - Estratégias de Ensino: Para se obter um bom resultado na aprendizagem dos alunos, alguns métodos e estratégias devem ser estabelecidos, com o auxílio de alguns recursos audiovisuais.

\section{- Metodologia e Recursos audiovisuais:}

- Exposição oral (Aulas dialogadas/ microaulas, etc.);

- Dinâmicas de grupo (seminários, discussão e debates em grupo, Tempestade Cerebral, pesquisa, vivências, etc.)

- Data show, computador, lousa, pincel anatômico, etc.

\subsection{6 - Referências}

A bibliografia da disciplina reúne livros, artigos, teses e dissertações e é dividida em:

- Básica (algumas delas): BEHAR ${ }^{[6]}$, CORTELAZZO ${ }^{[8]}$; LITTO; FORMIGA ${ }^{[9]}$; MOORE ${ }^{[10]}$, e TORI ${ }^{[11]}$;

- Complementar, para apoio, aprofundamento e pesquisa dos assuntos abordados, que podem ser alguns artigos das revistas de referência: Revista Brasileira de Educação a Distância, Revista Brasileira de Aprendizagem Aberta e a Distância da Associação Brasileira de $\mathrm{EaD}$, American Journal of Distance Education, Canadian Journal of Learning and Technology, dentre outros.

4.2.7 - Critérios de Avaliação: - A avaliação se efetuará de forma contínua. Atenderá também a um caráter de formalidade assim estabelecido:

- Avaliação diagnóstica: ocorrerá no início do curso, para identificar o perfil do aluno e os pré-requisitos de entrada.

- Avaliação Formativa: ocorrerá gradativamente ao longo do curso, à medida que as unidades forem se consolidando, tendo como critérios: relatórios, exercícios, seminários, pesquisas, provas, entre outros.

- Avaliacão Somativa: ocorrerá no final do curso. Será efetivada com a soma de todos os critérios avaliativos consolidados, devendo culminar com a aprovação do aluno que obtiver 
nota igual ou superior a $5(\mathrm{~A}=$ de 9 a $10 ; \mathrm{B}=$ de 7 a $8.9 ; \mathrm{C}=$ de 5 a 6.9 ; reprovado=nota inferior a 5), tendo em vista finalmente, com conceito estabelecido.

\section{- Instrumentos de avaliacão:}

- $\quad$ Portfólio;

- $\quad$ Produção de Trabalhos Científicos.

\section{Resultados e Discussões}

A proposta que apresentamos para uma disciplina em EaD baseia-se em Eixos Temáticos. Estes caracterizam-se como o agrupamento de temas, com a finalidade de facilitar a organização dos assuntos, de maneira ampla e abrangente, possibilitando o encadeamento lógico dos conteúdos e sua problematização, além da abordagem histórica na análise dos temas. Estes eixos estão em constante aprimoramento e mudança.

Para tanto, a definição de cada eixo emergiu a partir da visão exposta e buscou valorizar aspectos que viabilizassem uma melhor compreensão pelo aluno, além de instigá-lo a contribuir constantemente com suas ideias e conhecimentos.

Tivemos também como orientação, a abordagem interacionista, que foca na flexibilidade para a elaboração do curso e permite uma adaptação do conteúdo às necessidades do aluno, valorizando o processo de ensino e aprendizagem ${ }^{[12]}$.

É importante utilizarmos um método de educação baseado no diálogo entre professor e aluno, onde haja experiências de cada um no outro. A imposição do conhecimento de forma moldada e findada não pode aparecer nesta estrutura didático-pedagógica. $\mathrm{O}$ aluno deve se sentir compelido a questionar, sugerir e criticar, sem a sensação que será punido ${ }^{[13]}$.

Assim, a partir desta perspectiva, no eixo 1 - Gestão, Planejamento e Estruturação da $\mathrm{EaD} \mathrm{-} \mathrm{,} \mathrm{contemplamos} \mathrm{a} \mathrm{base} \mathrm{histórica} \mathrm{e} \mathrm{constituínte} \mathrm{da} \mathrm{EaD}$, incluíndo seus aspectos metodológicos, a fim de perceber que a EaD tem sua origem e corpo bem definidos. Os tópicos utilizados neste eixo, são de fundamental importância, por introduzir o aluno ao “mundo EaD" e, assim, dar credibilidade àquilo que hoje estudam e, no futuro, poderão trabalhar.

O Eixo 2 - Os Sujeitos no EaD - foi dedicado aos atores principais desta proposta, que são os alunos e professores/tutores.

Acreditamos que entender quem são estes personagens/atores e seu perfil favorece a compreensão do que e como poderá oferecer suas aulas/tutorias/curso. Configura-se, assim, 
um eixo imprescindível de ser explorado para que estes alunos, de fato, possam contribuir de forma signitificativa para o desenvolvimento educacional do país, democratizando o saber.

Já no Eixo 3 - Estratégias atuais na EaD -, possui grande valor no que concerne a prática em ensino à distância. Este eixo busca trabalhar o aqui e agora no ensino, conceitos e concepções em EaD e suas implicações, destacando-se seus desafios e desdobramentos pedagógicos.

O Eixo 4 - Instrumentos e Recursos didático-pedagógicos - foi dedicado a uma demonstração geral das possibilidades de ferramentas em EaD, as quais não se restringem apenas ao uso do computador. Este eixo está, intimamente, ligado as propostas didáticopedagógicas e merece uma atenção mais focada, já que trabalha a produção e oferta de materiais didáticos.

Já no Eixo 5 - Tendências do EaD - , vislumbram-se as possibilidades de Educação a Distância para um futuro próximo e seus desafios. É o momento propício para reflexão e debates, a fim de obtermos avanços na área. Além deste trabalho, voltamos o olhar a educação em saúde, que é o contexto em que esta disciplina está ocorrendo.

Esta estrutura, como dissemos, é estável e, ao mesmo tempo, mutável, por valorizar a experiência do aluno e o avançar progressivo no conteúdo. Contempla metas a curto e a longo prazo, que se concretizariam não apenas ao final do curso, e sim quando necessitarem utilizar em algum momento em sua vida e, ainda assim, em constante engendramento. Isto propicia que o aluno encontre sentido no que está fazendo, justamente por compreender o que faz e a contribuição à sua auto-formação.

\section{Considerações Finais}

O que aqui expusemos é uma proposta de estruturação de uma disciplina em $\mathrm{EaD}$, que não busca limitar a prática docente. Valorizamos ao máximo que esta seja uma proposição em constante mudança. Na verdade, esperamos que sugira os caminhos que podem ser trilhados, pois reconhecemos que o começo nem sempre é fácil.

Por compreendemos que esta é apenas uma ideia, acreditamos que mereça críticas e sugestões ao desenvolvimento e aperfeiçoamento. Como seres em constante evolução, não consideramos que esta é a forma final desta disciplina e, por isso, estará igualmente evoluindo. 
Apesar disso, depreendemos que estes passos, igualmente, facilitem a construção e divulgação de disciplinas em Instituições Públicas de Ensino, pois, esta realidade ainda é resquícia nestes centros de saber.

Nesta perspectiva, os conteúdos abordados através dos eixos temáticos também valorizam a proposta de reestruturação do ensino preconizada por nosso Governo. Acredita-se que, por meio destes eixos, possamos aprimorar, intensificar e motivar a aprendizagem, além de proporcionamos ao aluno uma preparação para a vida em sociedade e o conhecimento do mundo que o cerca.

Esta visão continuamente está sendo corroborada com os frutos que a disciplina apresentou, como alunos, de turmas anteriores, que estão inseridos no mercado profissional em EaD e que relatam sua utilidade na prática. A partir do ensinamento contruído em pares nesta formação, puderam embasar seus saberes.

\section{Referências}

${ }^{[1]}$ BRASIL, Ministério da Educação.Decreto 5.622 de 19/12/05. 2005.

${ }^{[2]}$ VEIGA, Ilma Passos Alencastro (Coord.). Didática Pedagógica. $21^{\text {a }}$ ed. Campinas (SP): Papirus, 2004.

[3] BELlONI, Maria Luiza. Educação a Distância. $5^{\mathrm{a}}$ ed. Campinas (SP): Editores Associados, 2008.

${ }^{[4]}$ KENSKI, Vani Moreira. Tecnologias e ensino presencial e a distância. Campinas (SP): Papirus, 2003.

[5] OLIVEIRA, Elsa Guimarães. Educação a distancia na transição paradigmática, Campinas (SP): Papirus, 2003.

${ }^{[6]}$ BEHAR, Patricia Alejandra et al. Modelos Pedagógicos em Educação a Distância. Porto Alegre: Artmed, p.17, 2009 
${ }^{[7]}$ BUENO, S.M.V. Tratado de educação para a saúde. Ribeirão Preto - SP: FIERP/ EERP-USP, 2010.

${ }^{[8]}$ CORTELAZZO, I.B.C. Prática pedagógica, aprendizagem e avaliação em Educação a Distancia. Curitiba: IBPEX, $2^{\mathrm{a}}$ Ed., 2010.

${ }^{\text {[9] }}$ LITTO, F. M.; FORMIGA, M. M. M. (Org.). Educação a distância: o estado da arte. São Paulo: Pearson Education do Brasil, 2009.

[10] MOORE, M. G. (Ed.). Handbook of distance education. 2nd. ed. Mahwah, NJ: Lawrence Erlbaum, 2007.

${ }^{[11]}$ TORI, R. Educação sem distância: as tecnologias interativas na redução de distâncias em ensino e aprendizagem. São Paulo: Editora SENAC, 2010.

${ }^{[12]}$ FRANCO, Marcelo Araújo (Org.) Orientações para o desenvolvimento de cursos mediados por computador - Campinas (SP): Centro de Computação da UNICAMP, 2003.Disponível em <http://www.rau-tu.unicamp.br/nou-rau/ead/document/?view=24> Acessado em: 08/05/2012.

${ }^{[13]}$ FREIRE, P. Pedagogia da autonomia: saberes necessários à prática educativa. São Paulo: Paz e Terra, 1996.

[14] Pedagogia do Oprimido. São Paulo (SP): Paz e Terra, 2010. 